HELMINTHOLOGIA, 58, 1: 85 - 91, 2021

\title{
Description of Prionchulus girchi sp. nov. (Nematoda: Mononchina) with additional data on two known species of the genus Prionchulus from Lorestan province, Iran
}

\author{
E. BAZGIR*, A. NAGHAVI, Z. ZOLFAGHARI \\ Laboratory of Nematology, Department of Plant Protection, Faculty of Agriculture, Lorestan University, Khorramabad, Iran, \\ *E-mail: bazgire14@gmail.com
}

Article info

Received April 27, 2020

Accepted December 1, 2020

\section{Summary}

Three species of mononchids belonging to the Prionchulus Cobb, 1916 genus, one new and two previously known species collected from natural ecosystem of Khorramabad county, Lorestan province, south west of Iran, are described. Prionchulus girchi sp. nov. is morphologically characterized by its $2.1-2.2 \mathrm{~mm}$ body length, numerous cuticular pores, slightly offset lip region, prominent labial and cephalic papillae, cephalic papillae larger than labial ones, barrel-shaped and spacious (40 $-43 \times$ $22.5-24 \mu \mathrm{m}$ ) buccal cavity, weakly rounded tail tip and weakly expressed tail tip's hyaline. In this study, $P$. fagi and $P$. muscorum were also collected and some additional data of these two species are also given.

Keywords: Crataegus aronia; Mononchida; new species; Prionchulus girchi sp. nov.; Prionchulus fagi; Quercus libani

\section{Introduction}

Mononchid nematodes as a group sensitive to habitats disturbances are considered as indicators of ecological changes (Johnson, et al. 1974; Bongers, 1990). The order Mononchida has been proposed by Jairajpuri (1969), which include two superfamily and forty-nine genera (Ahmad \& Jairajpuri, 2010). The genus Prionchulus comprises of more than thirty three species, which have been described from various parts of the world (Jana et al., 2010; Vu et al., 2018; Winiszewska \& Susulovsky, 2003; Zell, 1985), but only three species of this genus have been described and reported from Iran (Ghaderi et al., 2012; Naghavi et al., 2017). Prionchulus species are characterized by large and barrel-shaped buccal cavity, dorsal tooth stout, situated in anterior half of buccal cavity, opposed subventral denticulate ridges, pharyngo-intestinal junction non-tuberculate, female genital system amphidelphic (Ahmad \& Jairajpuri, 2010). In this study P. girchi sp. nov. and two other known species viz. P. fagi and P. muscorum have been collected and studied using a discriminant analysis based on their most important morphological characters within this genus of Mononchids in Khorramabad County, Lorestan province, Iran.

\section{Material and Methods}

Nematode surveys were conducted from 2017 to 2018 in natural ecosystem of Khorramabad County, Lorestan province, south west of Iran. Soil samples were collected from the $5-30 \mathrm{~cm}$ depth of forest soils and processed in the Laboratory of nematology in Lorestan University, Khorramabad, Iran. Nematodes were extracted from $250 \mathrm{~cm}^{3}$ of soil samples, adapting Brown \& Boag (1987) modified method. Specimens to be used for light microscopy studies were killed and transferred to dehydrated glycerin, and then permanent microscopic slides of the nematodes were prepared. Morphological and morphometric characters of nematodes were examined and photographed using an Olympus Bx31 light microscope equipped with a Dino-eye microscope eye-piece camera in

\footnotetext{
$\bar{*}$ - corresponding author
} 
Table 1. Morphometrics of Prionchulus girchi sp. nov. from Lorestan, Iran. All measurements are in $\mu \mathrm{m}$ (except for $\mathrm{L}$ in $\mathrm{mm}$ ) and are in the form: mean $\pm s . d$. (range).

\begin{tabular}{|c|c|c|c|}
\hline $\begin{array}{l}\text { Location } \\
\text { Character* }\end{array}$ & \multicolumn{2}{|c|}{ Chenar Shureh (Type) } & Imanabad \\
\hline$n$ & Holotype & Paratype $(n=3)$ & Female $(n=2)$ \\
\hline $\mathrm{L}$ & 2.2 & $2.2 \pm 0.8(2.1-2.3)$ & $2.1,2.1$ \\
\hline a & 30.7 & $28.7 \pm 1.3(26.6-30.7)$ & $20.7,23.7$ \\
\hline b & 4.14 & $4.1 \pm 0.1(4.0-4.3)$ & $4.0,4.3$ \\
\hline c & 18.9 & $17.7 \pm 0.4(17.0-19.0)$ & $15.5,16.3$ \\
\hline$c^{\prime}$ & 3.6 & $3.3 \pm 0.1(3.0-3.6)$ & $2.7,3.1$ \\
\hline $\mathrm{v}$ & 67.0 & $66.0 \pm 0.8(65.0-67.0)$ & $65.0,66.0$ \\
\hline $\mathrm{G}_{1}$ & 17.0 & $18.6 \pm 1.1(17.0-21.0)$ & $22.0,22.0$ \\
\hline $\mathrm{G}_{2}$ & 14.0 & $16.3 \pm 2.1(14.0-20.0)$ & $19.0,20.0$ \\
\hline Buccal cavity length & 42.5 & $42.0 \pm 0.4(41.0-42.5)$ & $40.0,43.0$ \\
\hline Buccal cavity diameter & 24.0 & $22.9 \pm 0.3(22.5-24.0)$ & $23.0,24.0$ \\
\hline Lip region width & 43.0 & $43.3 \pm 2.4(43.0-44.0)$ & $44.0,44.5$ \\
\hline Neck length & 527.3 & $526.6 \pm 3.5(522.0-530.0)$ & $496.0,517.0$ \\
\hline Nerve ring from anterior end & 160.0 & $160.8 \pm 0.8(160.0-162.0)$ & $146.0,155.0$ \\
\hline Excretory pore from anterior end & 177.0 & $177.3 \pm 5.3(170.0-185.0)$ & $170.0,172.0$ \\
\hline Amphidial aperture diameter & 4.0 & $4.6 \pm 0.3(4.0-5.0)$ & $4.5,5.0$ \\
\hline Amphidial position from anterior end & 17.0 & $18.6 \pm 0.3(17.5-19.0)$ & $17.0,18.5$ \\
\hline Tooth length & 4.2 & $4.8 \pm 0.1(4.3-5.3)$ & $4.5,5.3$ \\
\hline Dorsal tooth from buccal base & 32.5 & $32.6 \pm 0.2(32.0-33.0)$ & $32.0,33.0$ \\
\hline Body diameter at neck base & 63.0 & $63.6 \pm 4.4(57.0-69.0)$ & $70.8,92.3$ \\
\hline Body diameter at mid body & 71.0 & $76.3 \pm 2.3(71.0-79.0)$ & $90.0,103.0$ \\
\hline Body diameter at anal region & 31.0 & $37.5 \pm 3.3(31.0-41.0)$ & $44.0,48.0$ \\
\hline Tail & 115.0 & $124.6 \pm 6.6(115.0-135.0)$ & $131.0,138.0$ \\
\hline
\end{tabular}

*total body length (L), body length/greatest body width (a), body length/neck length (b), body length/tail length (c), tail length/tail diameter at anus region (c'), \% distance of vulva from anterior end/body length (V), \% length of anterior female genital branch in relation to body length (G1), \% length of posterior female genital branch in relation to body length (G2).

conjunction with Dino Capture version 2.0 software. Raw photographs were edited using Adobe® Photoshop ${ }^{\circledR}$ CS. Drawing and photoplate were prepared by Corel DRAW ${ }^{\circledR}$, software version 12. Nematodes were identified at specific level using available identification keys (Ahmad \& Jairajpuri, 2010 and Jana et al., 2010).

\section{Ethical Approval and/or Informed Consent}

The conducted research is neither related to human nor animals use.

\section{Results and Discussion}

\section{Prionchulus girchi sp. nov.}

(Figs. 1, 2)

Measurements

See table 1.

\section{Description}

\section{Female}

Body medium sized, open 'C'-shaped upon fixation, more curved in tail region. Body tapering towards both ends. Cuticle smooth, relatively thin, $4.2-5.3 \mu \mathrm{m}$ thick in mid-body with numerous pronounced body pores along body length. Lip region offset by slightly depression, ca $4.2-4.4$ times as wide as high, with large conical and prominent labial and cephalic papillae, cephalic papillae larger than labial ones, amphidial apertures oval at level of dorsal tooth apex, buccal cavity barrel-shaped, $1.7-1.9$ times as long as it is wide with funnel-shaped base, dorsal wall at the level of dorsal tooth apex 4.4 - 4.8 $\mu \mathrm{m}$ thick, dorsal tooth medium-sized, its apex located at $9-10 \mu \mathrm{m}$ from anterior end of the sclerotized buccal cavity and $17.5-19 \mu \mathrm{m}$ from anterior end, subventral walls with two longitudinal, denticulate ridges, subventral denticles $8-10$ in number, distance between first and last denticle $15-17 \mu \mathrm{m}$. Pharynx cylindrical and muscular ca $22-25 \%$ of the body length, 


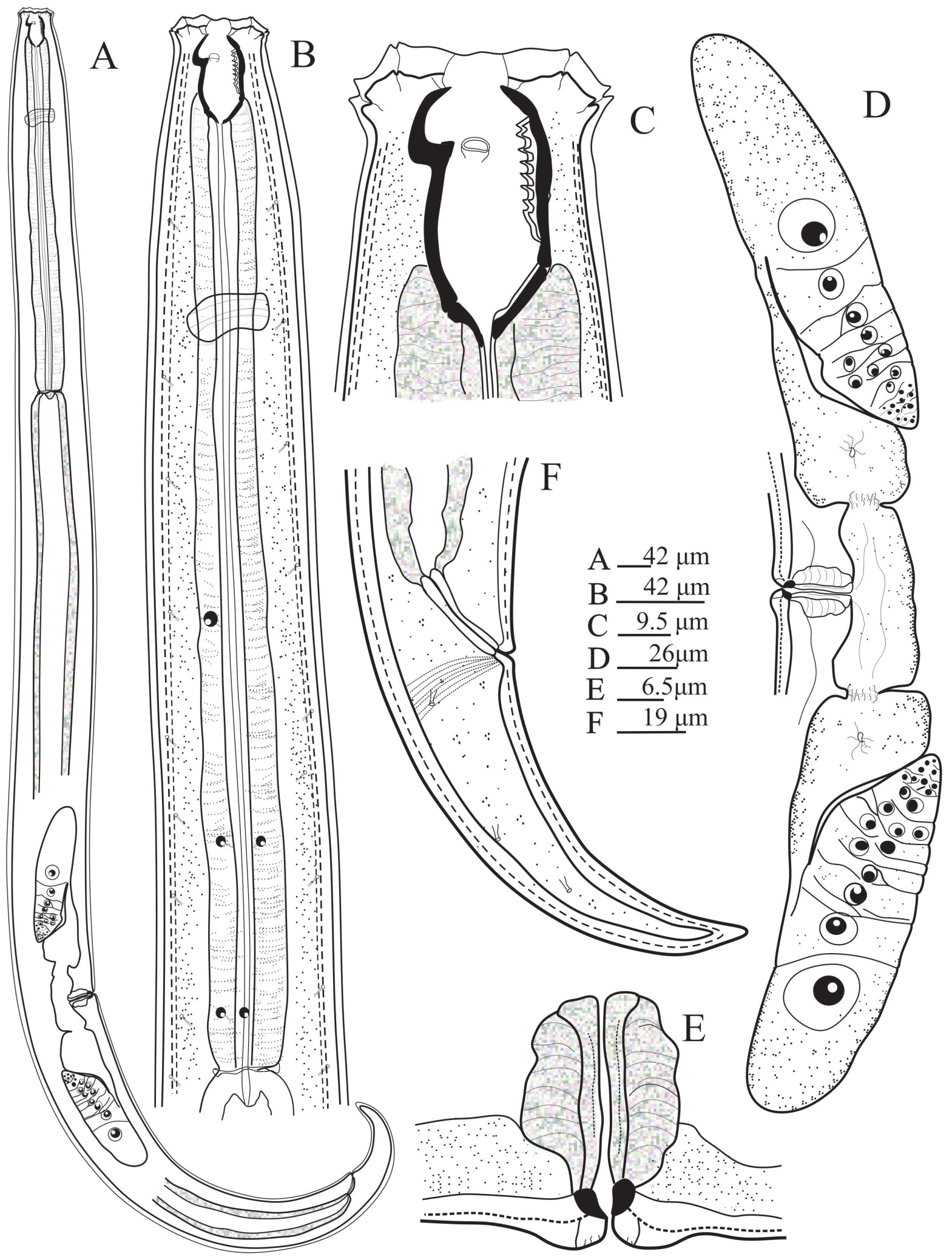

Fig. 1. Prionchulus girchi sp. n. A: Entire female body; B: Neck region; C: Anterior end; D: Female reproductive system; E: vaginal region; F: Caudal region. 
Table 2. Morphometrics of Prionchulus fagi Zell, 1985 and P. muscorum (Dujard, 1845) Wu \& Hoppli, 1929. All measurements are in $\mu \mathrm{m}$ (except for L in mm) and are in the form: mean \pm s.d. (range).

\begin{tabular}{|c|c|c|c|}
\hline \multirow{2}{*}{$\begin{array}{l}\text { Species } \\
\text { Location }\end{array}$} & \multirow{2}{*}{$\begin{array}{c}\text { P. fagi } \\
\text { Hamvar-Kulivand }\end{array}$} & \multicolumn{2}{|c|}{ P. muscorum } \\
\hline & & Robatnamaki & Imanabad \\
\hline$n$ & Female $(n=4)$ & Female $(n=4)$ & Female $(n=3)$ \\
\hline $\mathrm{L}$ & $2.8 \pm 0.9(2.7-3.0)$ & $2.1 \pm 0.8(1.9-2.2)$ & $2.7 \pm 0.2(2.7-2.8)$ \\
\hline a & $27.0 \pm 1.2(26.5-29.5)$ & $21.8 \pm 0.9(20.0-23.5)$ & $24.6 \pm 0.4(24.0-25.0)$ \\
\hline b & $4.2 \pm 0.1(4.0-4.4)$ & $4.2 \pm 0.1(4.0-4.4)$ & $4.6 \pm 0.1(4.4-4.8)$ \\
\hline c & $15.5 \pm 0.8(14.5-16.5)$ & $16.9 \pm 0.3(16.2-18.5)$ & $17.3 \pm 0.4(16.5-17.8)$ \\
\hline$c^{\prime}$ & $3.2 \pm 0.1(3.0-3.3)$ & $2.9 \pm 0.3(2.4-3.7)$ & $2.9 \pm 0.1(2.8-3.2)$ \\
\hline $\mathrm{v}$ & $65.8 \pm 0.7(64.0-66.5)$ & $65.0 \pm 0.7(64.0-67.0)$ & $64.6 \pm 0.3(64.0-65.0)$ \\
\hline $\mathrm{G}_{1}$ & $19.3 \pm 0.4(18.5-21.0)$ & $20.5 \pm 1.2(18.0-23.0)$ & $22.0 \pm 0.8(21.0-23.0)$ \\
\hline $\mathrm{G}_{2}$ & $18.8 \pm 0.1(18.5-19.0)$ & $18.8 \pm 0.7(18.0-20.0)$ & $17.6 \pm 0.3(17.0-18.0)$ \\
\hline Buccal cavity length & $48.0 \pm 0.2(47.5-49.0)$ & $45.0 \pm 1.8(43.0-47.0)$ & $47.5 \pm 0.3(47.0-48.0)$ \\
\hline Buccal cavity diameter & $27.3 \pm 0.2(27.0-28.0)$ & $26.0 \pm 0.9(24.0-27.0)$ & $24.3 \pm 0.1(24.0-25.0)$ \\
\hline Lip region width & $48.0 \pm 1.2(46.0-49.5)$ & $45.5 \pm 1.2(43.0-47.0)$ & $48.2 \pm 0.8(46.5-49.5)$ \\
\hline Neck length & $650.0 \pm 15.2(630.0-670.0)$ & $504.5 \pm 13.8(490.5-519.0)$ & $587.5 \pm 6.5(580.0-600.0)$ \\
\hline Nerve ring from anterior end & $173.0 \pm 2.4(170.0-182.0)$ & $175.0 \pm 11.2(160.0-190.0)$ & $182.6 \pm 7.5(173.0-195.0)$ \\
\hline Excretory pore from anterior end & $211.0 \pm 1.8(209.0-213.0)$ & $206.0 \pm 3.4(200.0-210.0)$ & $211.0 \pm 4.5(204.0-216.0)$ \\
\hline Amphidial aperture diameter & $5.2 \pm 0.1(5.0-5.40)$ & $4.8 \pm 0.2(4.5-5.5)$ & $5.8 \pm 0.3(5.5-6.3)$ \\
\hline Amphidial position from anterior end & $18.2 \pm 0.2(17.0-18.5)$ & $16.0 \pm 0.4(15.0-17.0)$ & $16.0 \pm 0.2(15.0-16.5)$ \\
\hline Tooth length & $10.0 \pm 0.8(9.5-11.0)$ & $10.0 \pm 0.1(9.8-10.2)$ & $9.7 \pm 0.1(9.5-10.0)$ \\
\hline Dorsal tooth from buccal base & $34.4 \pm 0.2(34.0-35.0)$ & $32.2 \pm 1.8(29.2-34.0)$ & $37.1 \pm 0.5(36.5-38.0)$ \\
\hline Body diameter at neck base & $96.0 \pm 4.2(90.0-101.5)$ & $85.2 \pm 4.1(80.0-90.0)$ & $91.0 \pm 1.3(88.5-92.5)$ \\
\hline Body diameter at mid body & $105.0 \pm 1.8(103.0-107.5)$ & $99.2 \pm 6.1(92.0-110.0)$ & $111.3 \pm 0.5(110.0-112.0)$ \\
\hline Body diameter at anal region & $58.2 \pm 1.1(57.0-59.5)$ & $43.6 \pm 5.2(31.0-50.0)$ & $54.5 \pm 2.2(52.0-57.0)$ \\
\hline Tail & $194.2 \pm 3.1(190.0-200.0)$ & $126.0 \pm 5.3(117.0-136.0)$ & $161.1 \pm 4.3(155.5-168.0)$ \\
\hline
\end{tabular}

nerve ring at $28-31 \%$ of neck length, excretory pore weakly marked, in some specimens at $32-34 \%$ of neck length. Orifices of the pharyngeal glands: DO at ca $55-59 \%$, SV101 and SV 102 at ca $77-79 \%$, and SV2O1 and SV2O2 at ca $94-96 \%$ of pharyngeal length, pharyngo-intestinal junction non-tuberculate. Genital branches nearly symmetrical, anterior branch 363 $468 \mu \mathrm{m}$, posterior $300-451 \mu \mathrm{m}$ long, Ovaries straight, reflexed and with one row of oocytes, anterior ovary $127-197 \mu \mathrm{m}$, posterior $107-202 \mu \mathrm{m}$ long, not reaching to the uterus oviduct junction, oviduct short with well-marked pars dilatata, $95-110 \mu \mathrm{m}, 0.84$ -1.1 times the corresponding body diameter, uterus $48-56 \mu \mathrm{m}$ long, $0.57-0.69$ the corresponding body diameter. Vulva a transverse slit with, protruding lips, located posterior to middle of the body, vagina perpendicular to the body axis, extending inwards for $40-45 \%$ of the body diam., pars proximalis $23-26 \mu \mathrm{m}$ long with sigmoid contours and surrounded by strong circular musculature, pars refrengens $3-4.5 \mu \mathrm{m}$ long with two drop shaped sclerotizations, pars distalis vaginae short, thick walled. Rectum almost straight, $38-40 \mu \mathrm{m}$ and $0.89-0.98$ times the anal body diameter. Tail conical, slightly ventrally bent, regularly tapering with three to four caudal pores on each side, tail terminus with weakly rounded tip, hyaline area of tail $7.5-7.8 \mu \mathrm{m}$ long and weakly expressed, without caudal glands and spinneret.

Male: Not found.

\section{Type locality and Habitat}

The new species collected from Chenar shureh village, Khorramabad County, Lorestan province, Southwest Iran, (GPS coordinates: $\mathrm{N} 33^{\circ} 14^{\prime} 47^{\prime \prime} \mathrm{E} 48^{\circ} 46^{\prime} 59^{\prime \prime}$, altitude $1790 \mathrm{~m}$ a.s.I.), in the rhizosphere of Hawthorn (Crataegus aronia L.) and from Imanabad village, Azna area, Khorramabad County, Lorestan province,

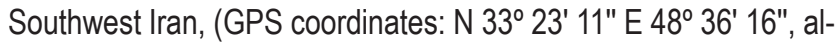
titude $1661 \mathrm{~m}$ a.s.I.), in the rhizosphere of Oak (Quercus libani L.). Type material

Holotype and paratype females deposited in the Collection of the Nematology Laboratory, Lorestan University.

\section{Diagnosis and Relationships}

The new species is characterized by a medium body size, numerous distinct cuticular pores, slightly offset lip region, prominent labial and cephalic papillae, cephalic papillae larger than labial ones, barrel-shaped and spacious ( $40-43 \times 22.5-24 \mu \mathrm{m})$ buccal cav- 

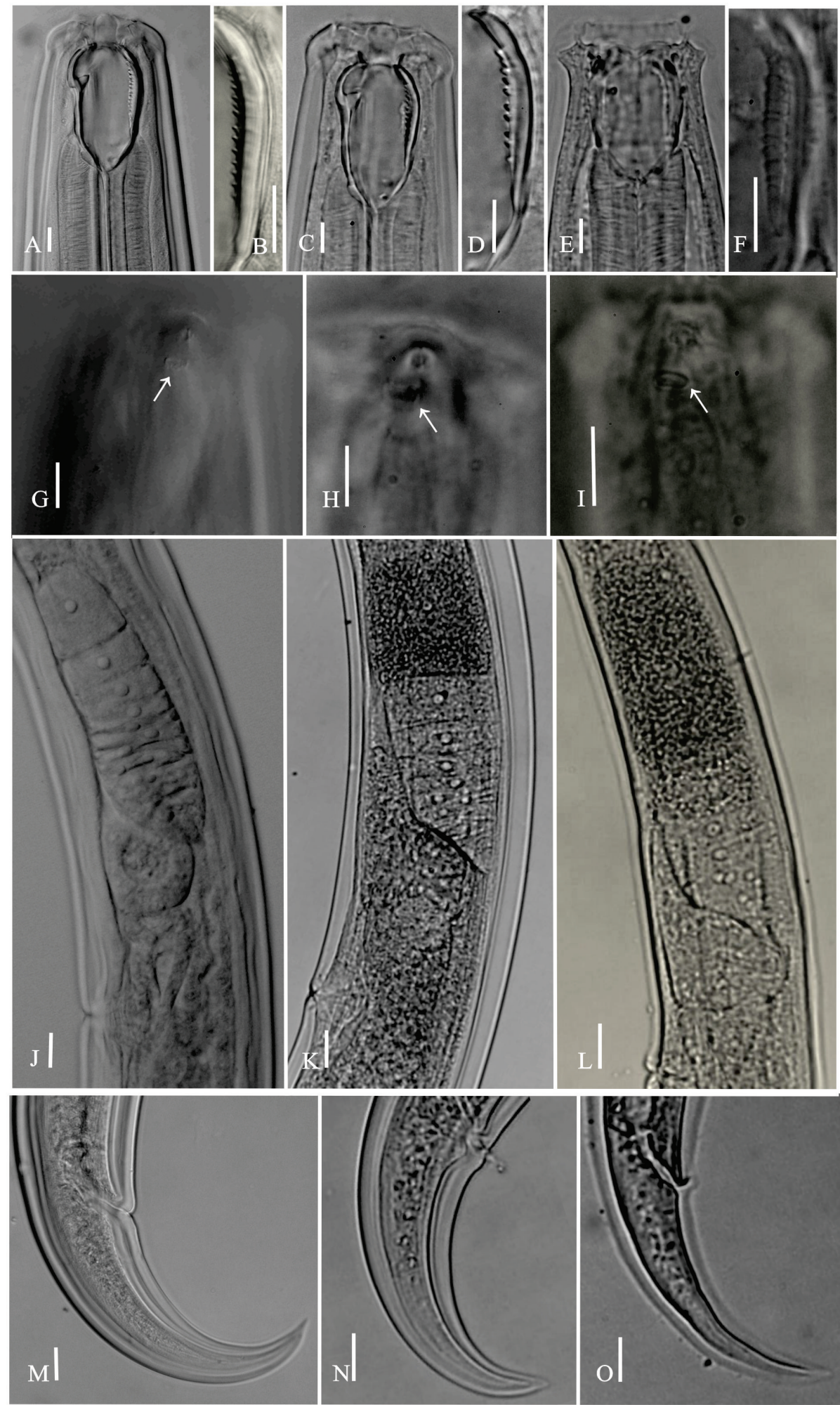

Fig. 2. A, B, G, J, M: Prionchulus fagi Zell, 1985. A: Anterior region; B: Sub ventral denticles; G: Amphidial aperture, J: Anterior genital branch, M: Caudal region, C, D, H, K, N: P. muscorum (Dujardin, 1845) Wu \& Hopperli, 1929. C: Anterior region; D: Sub ventral denticles; H: Amphidial aperture, K: Anterior genital branch, $\mathrm{N}$ : Caudal region, E, F, I, L, O: P. girchi sp. nov. E: Anterior region; F: Sub ventral denticles; I: Amphidial aperture, L: Anterior genital branch, O: Caudal region. (Scale bar: $\mathrm{A}-\mathrm{I}=10 \mu \mathrm{m} ; \mathrm{J}-\mathrm{O}=20 \mu \mathrm{m}$.) 
ity, lower position of dorsal tooth (22 - $25 \%$ of the buccal cavity length), weakly rounded tail tip and weakly expressed hyaline, pars proximalis vaginae with arcuate walls, pars refringens vaginae with two drop-shaped sclerotizations; pars distalis vaginae short, thick walled. $P$. girchi sp. nov. is closely related to $P$. pinophilus Winiszewska \& Susulovsky, 2004, P. fistulous Susulovsky \& Winiszewska, 2002, P. auritus Andrassy, 1985 and P. muscorum (Dujardin, 1845) Wu \& Hoeppli, 1929. The new species is very similar to $P$. pinophilus (data from Winiszewska \& Susulovsky, 2004) are taken for comparative purposes), but $P$. girchi sp. nov. can be differentiated from $P$. pinophilus by the position of dorsal tooth apex from base of buccal cavity $(75-78 \%$ vs $84 \%)$, dorsal tooth length ( $3-3.3$ vs $5 \mu \mathrm{m}$ ), number of subventral denticles ( $8 \mathrm{vs} 12$ ), distance between first and last denticle (14.5 - $15.5 \mathrm{vs} 18.5 \mu \mathrm{m})$, distance of amphidial aperture from anterior end ( $11-12.5$ vs $8.6 \mu \mathrm{m})$, longer anterior (363 - 476 vs $250 \mu \mathrm{m})$ and posterior genital branches (300 - 451 vs $250 \mu \mathrm{m})$, posteriorly located vulva $(\mathrm{V}=65-67$ vs $61 \%)$ and caudal gland (absent vs spherical glandular bodies in proximal part). Morever, the new species can be differentiated from $P$. fistulous (original description by Susulovsky \& Winiszewska, 2002) by having narrower lip region ( $43-44.5$ vs $46.7-51.4 \mu \mathrm{m}$ ), shorter buccal cavity $(40-43$ vs $47.2-51 \mu \mathrm{m})$ and shorter tail $(115-138$ vs $124-177 \mu \mathrm{m}$ ). It can also be separated from $P$. auritus (see detailed description by Orselli \& Vinciguerra, 2007) by having narrower lip region ( $43-44.5$ vs $47-57.5 \mu \mathrm{m}$ ), shorter buccal cavity ( $40-43$ vs $43-49.5 \mu \mathrm{m}$ ), amphidial position (amphid at the level of apex of dorsal tooth vs anterior of dorsal tooth) and shorter tail (115 - 138 vs $145-195 \mu \mathrm{m})$. Finally, P. girchi sp. nov. differs from P. muscorum (data from Winiszewska \& Susulovsky, 2003) by the size of cephalic and labial papillae (lip region with large conical and prominent labial and cephalic papillae vs lip region rounded with small labial and cephalic papillae), subventral denticle numbers $(8-10$ vs $10-14)$, the size of cuticular pores (cuticle smooth with numerous distinguished body pore vs indistinct pores along the body), shorter buccal cavity ( $40-43$ vs $47.6-54.3 \mu \mathrm{m})$ and shorter tail $(115-138$ vs $140-209 \mu \mathrm{m})$.

\section{Etymology}

The specific epithet is derived from the Lori word Girch meaning howthorn (Crataegus aronia L), the plant which the P. girchi sp. nov. was collected from its rhizosphere for the first time.

\section{Prionchulus muscorum (Dujardin, 1845) Wu \& Hoeppli, 1929}

(Fig. 2)

Measrements

See Table 2.

Description:

Female

Body medium sized, open ' $C$ '-shaped upon fixation, more curved in tail region. Cuticle smooth, $3-4 \mu \mathrm{m}$ thick in mid body, Cuticular small pores, arranged along the body (excluding tail). Lip region rounded, $43-49.5 \mu \mathrm{m}$ wide, offset by a slightly depression, small labial and cephalic papillae, slightly raised, labial papillae are the same size as head papillae. Buccal cavity barrel-shaped, 43 $48 \times 24-27 \mu \mathrm{m}$. Dorsal tooth $9-10.2 \mu \mathrm{m}$ long, its apex located at $11-13.8 \mu \mathrm{m}$ from the anterior end of the buccal cavity, subventral ridges with $10-12$ well-developed denticles each. Amphidial aperture 5.5 - $6 \mu \mathrm{m}$ wide, located at the level of anterior end of buccal cavity, $14-16 \mu \mathrm{m}$ from anterior end. Pharynx cylindroid and muscular, $23-25 \%$ of the body length, nerve ring at $30-38 \%$ of the neck length. Reproductive system didelphic, amphidelphic, ovaries reflexed. Vulva post-equatorial, a transverse slit with sclerotized pars refringens. Tail conical, ventrally bent, tail tip weakly rounded, caudal glands and spinneret absent.

Male: Not found.

\section{Distribution}

Robat Namaki village, Robat area, Khorramabad County, Lorestan

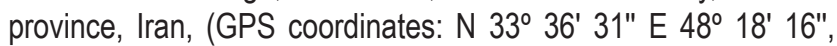
altitude $1332 \mathrm{~m}$ a.s.I.), in the rhizosphere of Hawthorn (Crataegus aronia L.), and Imanabad village, Azna area, Khorramabad County, Lorestan province, Iran, (GPS coordinates: N $33^{\circ} 23^{\prime} 11^{\prime \prime} \mathrm{E} 48^{\circ}$ $36^{\prime} 16^{\prime \prime}$, altitude $1661 \mathrm{~m}$ a.s.l.), in the rhizosphere of Oak (Quercus libani L.).

\section{Remarks}

Prionchulus muscorum is a very well-known species with worldwide distribution reported from many countries of Europe, Africa, America, Asia and Australia (Andrassy, 2009). In Iran, this species was first observed by Loof et al. (1990) in the rhizosphere of Oak; later on, this species obtained from different localities in the country from the rhizosphere of different plants. The present Iranian females fit well with described population by Jiménez Guirado et al. (1997) except for having smaller $c$ ratio (13 - 16 vs $16-18)$ and shorter tail (117 - 168 vs $142-211.5 \mu \mathrm{m})$. The main features of the specimens, also fit perfectly to those populations described by Winiszewska \& Susulovsky (2003) except for shorter buccal cavity ( $43-48$ vs $47.6-54.3 \mu \mathrm{m})$ and shorter tail $(117-168$ vs $140-209 \mu \mathrm{m})$.

\section{Prionchulus fagi Zell, 1985}

(Fig. 2)

Measurements

See Table 2.

\section{Distribution}

Hamvar-e Kulivand village , Bastam area, Selseleh County, Lorestan province, Iran, (GPS coordinates: N $33^{\circ} 44^{\prime} 34^{\prime \prime}$ E $48^{\circ}$ $10^{\prime} 04 "$ ", altitude $1875 \mathrm{~m}$ a.s.l.), in the rhizosphere of Hawthorn (Crataegus aronia L.).

\section{Remarks}

P. fagi was first described by Zell, 1985. It was later redescribed based on the type material by Winiszewska \& Susulovsky, 2003. In Iran, this species was first observed by Naghavi et al. (2016) from Lorestan and Ardabil provinces. The present survey lorestanian population perfectly fit with described specimens by Winiszewska \& Susulovsky, 2003. 


\section{Conflict of Interest}

Authors state no conflict of interest.

\section{Refrences}

Ahmad, W., JaIRAJPURI, M. S. (2010): Mononchida: The predaceous nematodes. In: Nematology monographs and perspectives. Vol. 7. Leiden-Boston: Brill, 298 pp.

ANDRÁSSY I. (2009): Free-living nematodes of Hungary. III. Pedozoologica Hungarica No. 5. Budapest, Hungary, Hungarian Natural History Museum, 608 pp.

ANDRÁSSY I. (1985): On the genus Mononchus Bastian, 1865 and Prionchulus (Cobb, 1916) Wu \& Hoeppli. 1929 (Nematoda: Mononchidae). Opusc Zool., Budapest, 21: 9 - 22

Bongers, T. (1990): The maturity index: An ecological measure of environmental disturbance based on nematode species composition. Oecologia, 83: 14 - 19

Brown, D. J. F., BoAg, B. (1987): An examination of methods used to extract virus vector nematodes (Nematoda: Longidoridae and Trichodoridae) from soil samples. Nematol Mediterr, 16(1): 93 - 99 Ghaderl, R., KaSHI, L., Karegar, A. (2012): The nematodes of Iran (based on the published reports until 2011). Tehran, Iran: Agricultural Extension and Education Publication, 371 pp.

JaIRAJPURI, M. S. (1969): Studies on Mononchida of India. I. The genera Hadronchus, lotonchus and Miconchus, and a revised classification of Mononchida, new order. Nematologica, 15: 557 581. DOI: /10.1163/187529269X00894

Jana, T., Dattaray, P., Ghosh, G., ChatterJee, A. (2010): First report of Prionchulus kralli (Mononchida:Nematoda) from India with a revised and updated key to species of the genus Prionchulus Cobb, 1916. Nematol Mediterr, 38: $59-65$

Johnson, S. R., FerrIS, J. M., FerRIs, V. R. (1974): Nematode com- munity structure of forest woodlots: III. Ordinations of taxonomic groups and biomass. J. Nematol., 6: $118-126$

Loof, P.A.A., BAROotI, S., KheYRI, A., (1990): Predatory nematodes (Mononchina) from Iran. Appl Entomol Phytopathol., 57(1 \& 2): 27 $-36$

Naghavi, A., Fallahi, A., Zhedi, E., Kazemi, E., Niknam, G. (2016): Records of fifteen predatory species of Mononchida from Iran. Procceding of $22^{\text {st }}$ Iranian Plant Protection Congress, Volume II Plant Diseases, Tehran University of Agricultural and Natural Resources, $258 \mathrm{p}$.

OrselLI, L. VinciguerRa, M.T. (2007): Three new and a rare species of Mononchida (Nematoda) from Ecuador. J Nematode Morphol System, 9: $137-146$

Susulovsky, A., WinIIZEESSKA G. (2002): Prionchulus fistulous sp. nov. (Nematoda: Mononchina) from Ukraine. Annal Zool., 52: 483 $-488$

Vu, T.T., Hallmann, J., Winiszewska, G. (2018): Description of a new predatory soil nematode Prionchulus sturhani sp. nov. (Nematoda: Mononchida). Annal Zool., 68(3): 403 - 408. DOI: 10.3161/00034 541ANZ2018.68.3.001

WiniszeWSKA, G., Susulovsky A. (2004): Revision of the genus Prionchulus Cobb, 1916 (Nematoda: Mononchina). I. Prionchulus spectabilis (Ditlevsen, 1911) Cobb, 1916 and related species. Annal Zool., 54: 491 - 509

WiniszewskA, G., Susulovsky, A. (2003): Revision of the genus Prionchulus Cobb, 1916 (Nematoda: Mononchina). I. Prionchulus muscorum (Dujardin, 1845) Cobb, 1916 and related species. Annal Zool., 53: 559 - 577

ZeLL, H. (1985): Nematoden eines Buchenwaldbodens 3. Prionchulus muscorum (Nematoda, Mononchida) [Nematodes of a beech wood soil 3. Prionchulus muscorum (Nematoda, Mononchida)]. Carolinea, $42: 57$ - 74 (In German) 